\title{
GABINETE DO DESENRASCANÇO ESTUDANTIL: A PROMOÇÃO DO SUCESSO ESCOLAR NA ESCOLA COMUNITÁRIA DE SÃO MIGUEL DE MACHEDE
}

\author{
Bravo Nico (1), Lurdes Pratas Nico (2), Patrícia Ramalho (3), \\ Ana Daniela Lopes (4), Vanessa Sampaio (5), Maria de Nazaré Pencas (6)
}

(1)Universidade de Évora \& Escola Comunitária de São Miguel de Machede/ SUÃO-Associação de Desenvolvimento Comunitário, ibn@uevora.pt

(2)Universidade de Évora \& Escola Comunitária de São Miguel de Machede/ SUÃO-Associação de Desenvolvimento Comunitário; Ipnico@uevora.pt

(3) (4) (5) (6) Escola Comunitária de São Miguel de Machede/

Suão-Associação de Desenvolvimento Comunitário, suao.fazerbem@gmail.com

\begin{abstract}
Resumo
O Gabinete do Desenrascanço Estudantil é um projeto comunitário de promoção do sucesso escolar em que se concretiza uma abordagem pedagógica baseada no mentorado e na tutoria, entre jovens da vila de São Miguel de Machede/Évora/Portugal.

Ao longo do ano letivo, os membros do Gabinete do Desenrascanço Estudantil participam em múltiplas atividades que compreendem o apoio pedagógico no estudo, a orientação vocacional e a realização de projetos de natureza comunitária e solidária que promovem a responsabilidade social individual e coletiva.
\end{abstract}

Palavras-Chave: Educação não formal, Educação Formal, Sucesso Escolar, Educação Comunitária

\begin{abstract}
The Gabinete do Desenrascanço Estudantil is a community project to promote school success that materializes a pedagogical approach based on mentoring and tutoring, among young people of the village of São Miguel de Machede/Évora/Portugal.

Throughout the school year, members of the Gabinete do Desenrascanço Estudantil participate in various activities that comprise the educational support in the study, vocational guidance and implementation of community and caring nature projects that promote individual and collective social responsibility.
\end{abstract}

Keywords: Non-formal Education, Formal Education, School Success, Community Education

\section{A COORDENADA INSTITUCIONAL}

A Suão - Associação de Desenvolvimento Comunitário foi fundada no ano de 1998, por um grupo de jovens que, preocupado com o seu futuro, na comunidade em que residia (São Miguel de Machede), entendeu que deveria assumir um papel mais ativo e interveniente na construção do seu destino. Neste contexto, foi decidido criar uma instituição que congregasse, em 
concomitância, três dimensões consideradas importantes para concretizar a finalidade enunciada: as dimensões social, juvenil e de desenvolvimento local. Estes três pilares ficaram materializados nos estatutos da instituição, uma vez que esta é, simultaneamente, IPSS (instituição particular de solidariedade social), associação juvenil (acreditada pelo Instituto Português do Desporto e da Juventude) e ADL (associação de desenvolvimento local). Desde o primeiro momento, assumiram-se, institucionalmente, as seguintes metas:

i) promover uma atitude positiva face ao futuro, por parte dos habitantes da vila;

ii) criar as melhores condições para os membros da comunidade exercerem, localmente, os seus deveres e direitos básicos de cidadania;

iii) identificar, valorizar e gerir, solidária e cooperativamente, os recursos endógenos da comunidade;

iv) envolver e promover parcerias com as instituições locais, fomentando o trabalho em rede e o desenvolvimento humano, social e económico local;

v) promover e valorizar a coesão intra e intergeracional.

O desenvolvimento local sustentável, a promoção da igualdade de oportunidades e a promoção da inclusão social apresentam-se como ponto de partida na preparação de todas as atividades educacionais e sociais promovidas.

É neste contexto institucional que, desde 1998, a Escola Comunitária de São Miguel de Machede - um dos projetos da SUÃO-Associação de Desenvolvimento Comunitário - tem vindo a construir e a concretizar um modelo pedagógico, no qual se valorizam e mobilizam, em simultâneo, os conhecimentos académicos (das gerações mais jovens e mais escolarizadas) e os conhecimentos experienciais (das gerações mais velhas e menos escolarizadas), numa simbiose que enriquece ambos os saberes (Nico \& Nico, 2011).

O projeto da Escola Comunitária de São Miguel de Machede abrange áreas tão diversas como a saúde, o trabalho (em particular, o trabalho jovem e qualificado), a solidariedade, 0 empreendedorismo social, a economia local, a cultura, a informação e a educação (Pacheco et al, 2011).

O modelo educativo da Escola Comunitária assume a educação não formal, como a sua base científica e pedagógica, baseada na cooperação intergeracional e na consideração e valorização dos recursos humanos endógenos, como elementos estruturantes dos projetos educativos. O projeto pedagógico e social da Escola Comunitária de São Miguel de Machede assume que a construção local de respostas, inovadoras e eficazes, para os desafios e problemas da comunidade contribui para a edificação de saberes e competências que, pela sua natureza estrutural e solidária, contribuirão para fortalecer as capacidades individual e coletiva e para a respetiva sustentabilidade, no território humano e social em que foram geradas.

O Gabinete do Desenrascanço Estudantil é, dentro deste quadro conceptual e pedagógico, um projeto que assumiu, desde a sua fundação, em 1999, a criação de condições para um, maior e melhor, exercício do direito à educação, por parte dos jovens estudantes da freguesia que frequentavam a escola formal, em todos os níveis de escolaridade. Para a concretização desta finalidade e de acordo com os anteriores pressupostos científicos e pedagógicos, assumiramse o mentorado e a tutoria juvenis, como os pilares da abordagem pedagógica que tem vindo a ser concretizada.

\section{O GABINETE DO DESENRASCANÇO ESTUDANTIL}

O projeto Gabinete do Desenrascanço Estudantil atravessa toda a história da Suão Associação de Desenvolvimento Comunitário, visto não ter sido interrompido, desde que se decidiu criar um grupo de apoio escolar a alunos que, vivendo num contexto, social e culturalmente desfavorecido, apresentavam altos níveis de insucesso e abandono escolares. Em 1999, no momento do início do projeto, os principais fatores que concorriam para esta grave situação escolar eram as seguintes: 
i) as difíceis transições entre os $4^{\circ}$ e $5^{\circ}$ e os $6^{\circ}$ e $7^{\circ}$ anos de escolaridade, que envolviam, em simultâneo, a transição de São Miguel de Machede para Évora, com todas as alterações escolares, pessoais e familiares envolvidas nesses processos de mudança;

ii) o, preocupante e assumido, baixo envolvimento das famílias nos percursos escolares dos mais jovens, uma realidade que decorria dos baixos índices de escolarização dos pais e da distância significativa entre a residência familiar e a localização dos estabelecimentos de ensino frequentados;

iii) a ausência de uma rede de transportes escolares adequada aos horários dos jovens e que causava a existência de períodos longos de espera, em Évora, facto que concorria para o aparecimento de comportamentos que desligavam os jovens da escola;

iv) a incapacidade das famílias em assegurarem, nos meios externos à escola, um apoio pedagógico que auxiliasse os seus filhos.

Neste contexto, no âmbito de um 'Projeto de Luta Contra a Pobreza' que, entretanto, a SUÃOAssociação de Desenvolvimento Comunitário estava a promover e contando com o impulso dado pela Professora Flamiana Freixial - Professora Primária, entretanto falecida e que atribuiu à instituição uma significativa quantia financeira para a promoção da Educação -, nasceu a ideia de se construir uma resposta local, de natureza endógena e que valorizasse os recursos existentes, para promover o sucesso escolar e a qualificação dos mais jovens. Nascia, assim, o Gabinete do Desenrascanço Estudantil.

Desde a sua fundação, o Gabinete do Desenrascanço Estudantil promoveu uma acentuada redução dos índices de insucesso e abandono escolares e procurou investir na gestão dos percursos de aprendizagem dos jovens, ao nível da procura, ativa e participada, de corredores vocacionais, da mediação entre as suas famílias e as escolas e da promoção de atividades, social e comunitariamente, responsáveis.

\subsection{A 'Tecnologia Educativa' do Gabinete do Desenrascanço Estudantil}

Os jovens a frequentar a escolaridade obrigatória constituem o grupo prioritário da intervenção realizada. Esta aposta na promoção de processos solidários de tutoria e mentorado entre os estudantes e na construção de percursos de qualificação sucedidos, que proporcionem, aos jovens, a oportunidade de considerarem, possível e útil, o acesso ao ensino superior e um posterior percurso profissional compatível com essa formação.

Ao longo do seu percurso de formação, cada estudante vai assumindo, de forma sucessiva, diferentes responsabilidades no projeto:

a) Tutorando e Mentorando: enquanto estudante do ensino básico e quando recebe apoio dos seus colegas mais velhos e mais experientes, na realização das suas tarefas escolares. Nesta fase, os jovens participam nas atividades, cumprindo um plano de trabalho pedagógico e vocacional, e intervêm em projetos comunitários de natureza social e solidária;

b) Mentor: enquanto estudante dos ensinos secundário e superior, o jovem inicia o seu percurso de mentor, assumindo a responsabilidade de apoiar os seus colegas mais novos e mais inexperientes. Simultaneamente, recebe apoio dos seus colegas mais velhos e que são tutores do projeto;

c) Tutor júnior: enquanto estudante do ensino superior, o jovem inicia um processo de maior nível de responsabilidade individual e institucional, assumindo o papel de tutor do projeto;

d) Tutor sénior: enquanto licenciado, alguns dos jovens assumem a responsabilidade de planificar, concretizar e monitorizar o projeto, assegurando que as tarefas são concretizadas e promovendo atividades de interesse geral da comunidade e que contam com a participação de todos os jovens;

e) Animador de projetos: em qualquer momento do percurso, qualquer jovem participa nas atividades da Escola Comunitária.

Em cada ano letivo, é estabelecido um plano de apoio pedagógico para os estudantes de todos os ciclos de ensino residentes em São Miguel de Machede. Nesse plano geral, é atribuído um papel fundamental aos estudantes universitários e aos recém-licenciados, valorizando as suas 
experiências estudantis e pessoais no estabelecimento de um processo de promoção do sucesso das aprendizagens escolares de todos os seus jovens colegas.

O esquema 1 apresenta, de forma sintética, o percurso padrão de um estudante de São Miguel de Machede, no âmbito do Gabinete do Desenrascanço Estudantil.

ESQUEMA 1 - Percurso de Formação do Estudante Micaelense

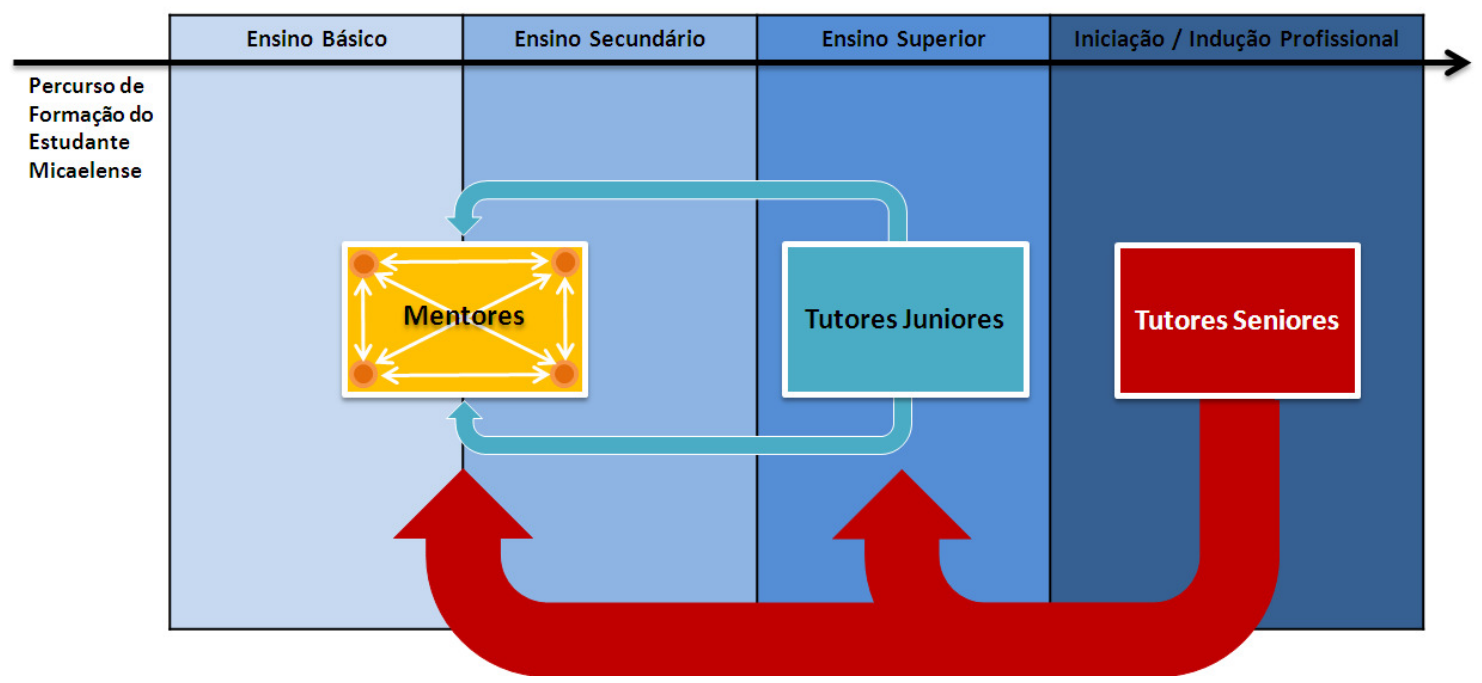

São conhecidos os efeitos positivos da técnica do mentorado (Welling, 1997), nomeadamente os que se prendem com o estabelecimento de uma relação humana e pedagógica entre indivíduos de idades próximas e com a construção e/ou reforço de competências de dimensão social que, neste contexto, pode ocorrer. $\mathrm{O}$ estudante envolvido em processos de mentorado pode, mais facilmente, motivar-se, uma vez que se pode identificar com um colega que sentiu problemas semelhantes aos seus, os conseguiu ultrapassar e que está, ali, a seu lado, disponível para o ajudar.

Dentro deste contexto conceptual e organizacional, os grupos possuem uma pequena dimensão, o que possibilita abordar os problemas académicos ou pessoais de forma mais eficaz e próxima. Nos grupos, os tutores do Gabinete do Desenrascanço Estudantil têm, como principal função, garantir que os seus colegas mais novos participam e se envolvem nas atividades propostas e, dessa forma, aumentam as possibilidades de garantirem aproveitamento escolar. Por outro lado, têm a responsabilidade de promover desafios e atividades de interesse a todos os participantes, tendo em conta as suas características pessoais.

No âmbito do processo de tutoria, deve referir-se a disponibilização de um serviço de orientação vocacional proporcionado por uma Psicóloga Educacional, que foi uma das jovens que realizou parte do seu percurso escolar no projeto. Neste âmbito, desenvolve-se, ao longo de cada ano letivo, um conjunto de atividades que tem, como finalidade, proporcionar experiências que disponibilizem conhecimento e contacto com realidades profissionais, aos jovens envolvidos.

O esquema 2 apresenta a organização geral do Gabinete do Desenrascanço Estudantil. 


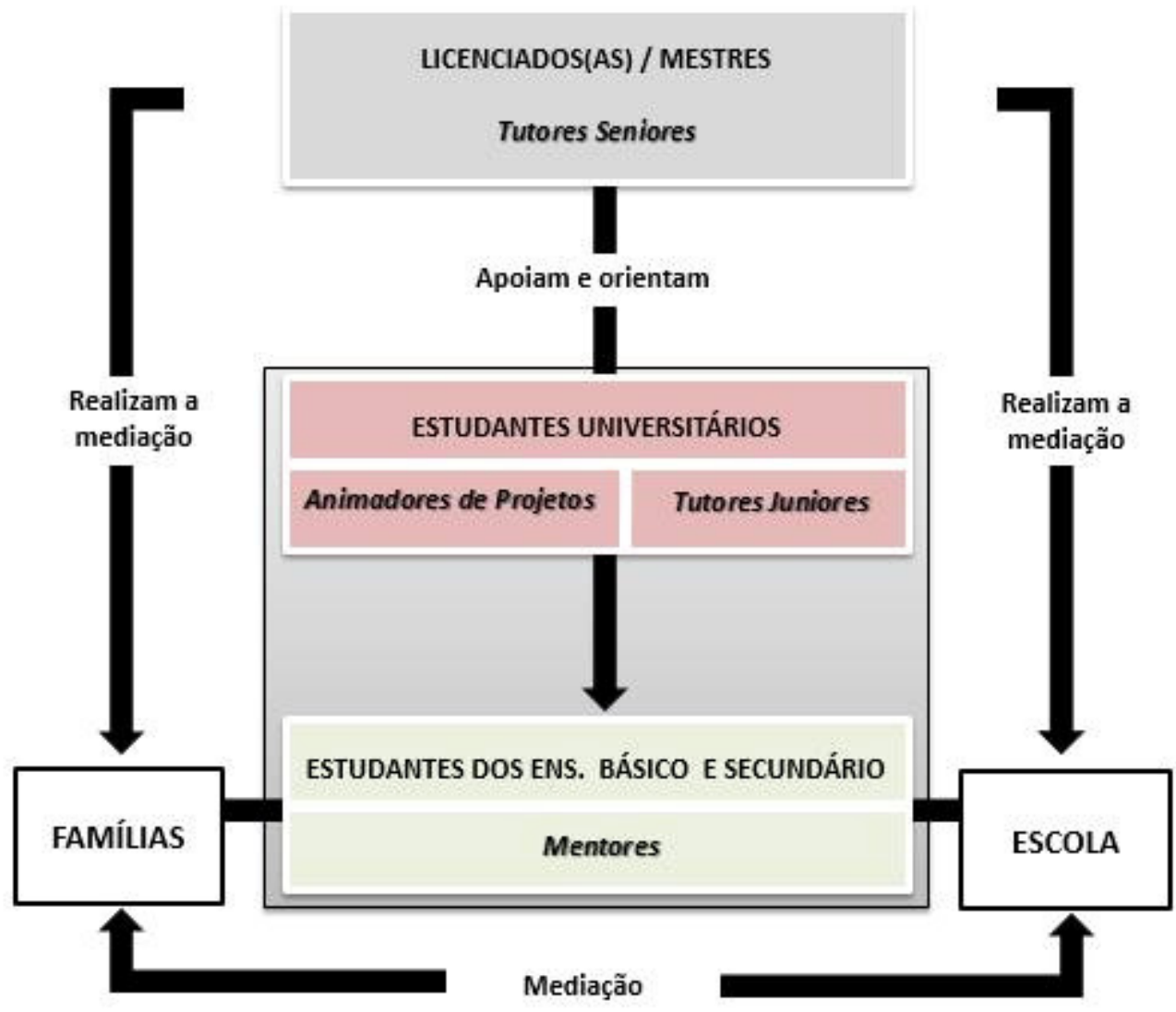

A atividade do Gabinete do Desenrascanço Estudantil organiza-se de acordo com o grupo de jovens de cada ano letivo e envolve uma planificação anual que contempla várias dimensões:

i) o apoio pedagógico disponibilizar e os meios necessários para o concretizar;

ii) a mediação entre a escola e as famílias, que é concretizado pelos tutores do projeto, nomeadamente os que já exercem funções profissionais na instituição;

iii) o apoio psicológico e a orientação vocacional já referidos;

iv) a promoção de projetos de âmbito comunitário com matriz intergeracional, envolvendo instituições locais e o acesso ao mercado de trabalho;

v) a concretização de estágios curriculares e profissionais, acessíveis aos que completam percursos longos de qualificação ( $12^{\circ}$ ano de escolaridade ou uma formação superior).

A participação e o envolvimento dos jovens no Gabinete do Desenrascanço Estudantil segue o modelo de apoio à aprendizagem PADéCa/Programa de Auxílio ao Desenvolvimento da Capacidade de Aprendizagem (Berbaum, 1992) e privilegia a cooperação intrageracional, numa interpretação local do modelo de aprendizagem proposto por Vygotsky (Fontes \& Freixo, 2004).

Neste quadro conceptual, cumprem-se os seguintes requisitos:

1. a participação é voluntária. No entanto, a partir do momento da adesão ao projeto, os participantes têm regras a cumprir: assiduidade na participação e resultados escolares. A não observância das regras - estabelecidas e aceites por todos - pressupõe a exclusão da participação;

2. no início do ano letivo, é assinado um Contrato de Educação e Solidariedade Comunitária, em que são signatários o jovem, o seu Encarregado de Educação e a SUÃO-Associação de Desenvolvimento Comunitário. A celebração deste contrato é um momento público e aberto à comunidade. No contrato, o jovem define os seus objetivos pessoais e assume a responsabilidade de trabalhar para os concretizar; 
3. privilegia-se a dimensão inclusiva da participação, no sentido de qualquer atividade dever ser participada por todos, independentemente da idade ou do nível de escolaridade frequentado;

4. as aprendizagens a promover são construídas de forma personalizada, atendendo ao perfil de cada jovem, nomeadamente às suas potencialidades e necessidades;

5. a participação no projeto deve proporcionar a tomada de consciência de uma oportunidade de alteração da realidade individual, no sentido de que, através da educação, se aumenta a capacidade de intervir no destino pessoal e coletivo (Freire, 2001).

\subsection{Os resultados do Gabinete do Desenrascanço Estudantil}

Ao longo dos 17 anos de funcionamento, participaram no Gabinete do Desenrascanço Estudantil cerca de 60 jovens, o que é uma significativa parte do universo de estudantes da freguesia, nesse período. Ocorreu apenas um episódio de abandono escolar e as reprovações verificaram-se em 5 (cinco) situações.

Um número significativo de jovens participantes (15) teve percursos escolares longos que culminaram numa licenciatura, sendo que todos estes licenciados se encontram, neste momento, a trabalhar. Cinco destes jovens tiveram a oportunidade de concretizar um Estágio Profissional na instituição que lhes proporcionou o apoio nos respetivos estudos.

No momento atual (2016), frequentam o ensino superior 2 (dois) jovens e uma recémlicenciada em Ciências da Educação frequenta um Estágio Profissional na Escola Comunitária de São Miguel de Machede, sendo uma das duas tutoras seniores do Gabinete do Desenrascanço Estudantil e uma das autoras deste texto.

Ao longo de todo o período de concretização do projeto, cerca de uma dezena destes jovens participou na atividade da instituição, enquanto responsáveis dos seus órgãos sociais. Atualmente, são 4 (quatro) os jovens nesta situação institucional.

Ao longo do período de funcionamento do Gabinete do Desenrascanço Estudantil, foram envolvidas 15 (quinze) instituições, como parceiros do projeto, destacando-se o contributo das seguintes:

i) Instituto Português do Desporto e da Juventude, que assegurou, todos os anos, o apoio ao funcionamento da instituição e o financiamento para a concretização de projetos de tempo livre, nas férias escolares;

ii) Instituto do Emprego e Formação Profissional, que apoiou na promoção e concretização de 5 (cinco) Estágios Profissionais frequentados por diplomados que frequentaram o projeto;

iii) Instituto da Segurança Social, no apoio prestado no âmbito do Centro Comunitário de São Miguel de Machede promovido pela SUÃO-Associação de Desenvolvimento Comunitário;

iv) Agrupamento de Escolas n. 4 de Évora, instituição frequentada pelos jovens estudantes da freguesia;

v) A Casa Agrícola Alexandre Relvas, empresa que apoia o projeto, através de protocolo celebrado no âmbito da sua política de responsabilidade social;

vi) O jornal Diário do SUL, que divulga as atividades desenvolvidas no projeto e que é um importante meio de certificação e valorização social das aprendizagens concretizadas;

Em cada ano letivo, em complemento das atividades regulares de apoio pedagógico, promovem-se outras iniciativas, nomeadamente:

i) visitas de estudo, nas quais se exploram assuntos que possam ser úteis para a consolidação vocacional das opções dos jovens ou para a exploração de alternativas nessa área;

ii) palestras informativas com temas de interesse do grupo e que decorram das atividades em curso; 
iii) um programa de atividades de Verão, com o qual se premeia o esforço realizado durante o período letivo e onde os jovens podem ocupar os seus tempos livres em atividades de lazer que proporcionam alguma retribuição financeira;

iv) atividades de natureza comunitária e social, através das quais os jovens devolvem, à comunidade, o investimento neles realizado.

O Gabinete do Desenrascanço Estudantil tem vindo a merecer o reconhecimento da sociedade civil, nomeadamente de algumas instituições que o têm distinguido com a atribuição de prémios ou através da sua divulgação:

i) em 2008, o projeto foi nomeado como um dos vencedores do Programa EDP Solidária 2008, promovido pela Fundação EDP;

ii) em 2014, o MIES - Mapa de Inovação e Empreendedorismo Social em Portugal atribuiu o Selo ES Mais ao projeto, considerando-o como uma iniciativa com elevado potencial de empreendedorismo social. Além da distinção, este organismo realizou um pequeno vídeo promocional que divulga $o$ projeto em seminários e encontros de interesse educacional e comunitário;

iii) em 2015, o Instituto Português do Desporto e da Juventude (IPDJ) considerou o projeto como um exemplo de referência, no âmbito do associativismo juvenil, atribuindo-lhe o Prémio Boas Práticas Associativas da Região Alentejo.

\section{CONCLUSÃO}

O Gabinete do Desenrascanço Estudantil, ao longo dos seus 17 anos de existência, assumiu um papel estrutural na comunidade de São Miguel de Machede. Tal evidência decorre do facto de este projeto ter contribuído para a concretização, em maior quantidade e melhor qualidade, do direito à Educação, por parte dos jovens, em todos os níveis de escolaridade.

A participação juvenil no projeto, por envolver diferentes níveis de envolvimento e de responsabilidade individual e coletiva, contribuiu para a consecução de objetivos de natureza social e para a construção de saberes e competências consideradas importantes para o exercício de uma cidadania plena e para a adequada integração no mundo do trabalho.

Por último, será de referir que o Gabinete do Desenrascanço Estudantil demonstra, à sua escala e dentro das circunstâncias territoriais, sociais e culturais em que foi fundado e desenvolvido, a importância das redes comunitárias, de natureza institucional e pessoal, no desenho, implementação e monitorização de políticas locais de educação e formação. Políticas que, na maior parte dos casos, são pensadas e concretizadas à medida das pessoas a quem se destinam.

Como muitas vezes se diz, a propósito do trabalho realizado no Gabinete do Desenrascanço Estudantil, a promoção do sucesso escolar, nesta pequena freguesia de um Alentejo despovoado e envelhecido é, sempre, um combate corpo a corpo, pessoa a pessoa. Pessoas que conhecemos, a quem tratamos pelos nomes e a quem ajudamos a concretizar os seus sonhos, tornando-os mais possíveis, tal como Paulo Freire nos recomendou (Freire, 2001).

Afinal, se não for para termos a liberdade de sonhar e para termos a capacidade de concretizar esses sonhos - moldando o nosso destino, à medida dos nossos projetos -, para que serve a Educação?

\section{Referências Bibliográficas}

Berbaum, J. (1992). Desenvolver a Capacidade de Aprendizagem. Lisboa: Escola Superior de Educação João de Deus.

Fontes, A. \& Freixo, O. (2004). Vygotsky e a Aprendizagem Cooperativa: uma forma de aprender melhor. Lisboa: Livros Horizonte. 
Freire, P. (2001). Pedagogia dos Sonhos Possíveis. São Paulo: Fundação Editora da UNESP(FEU)

Nico, B. \& Nico, L. (2011). Educação e território: o (des)encontro geracional das aprendizagens e a fratura cultural no Alentejo. in Marcia Alvarenga (Org.). Educação de Jovens e Adultos em tempos e contextos de aprendizagem. Rio de Janeiro: Editora Rovelle, pp.33-44.

Pacheco, D.; Ramalho, P.; Nico, B. \& Nico, L. (2011). Aprendizagens Comunitárias. in Bravo Nico \& Lurdes Nico (Orgs.) Escola(s) do Alentejo: um mapa do que se aprende no Sul de Portugal. Mangualde: Edições Pedago, pp. 45-48.

Welling, H. (1997). "Mentorado" Informação Geral: proposta para a realidade portuguesa, recuperado de http://docplayer.com.br/19955291-Mentorado-informacao-geral-propostapara-a-realidade-portuguesa-1-introducao.html 